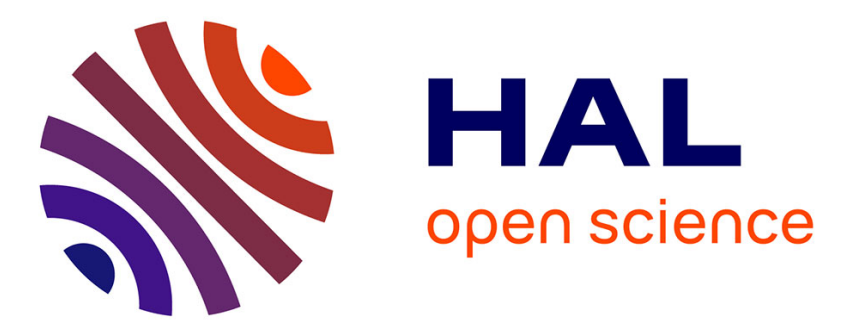

\title{
Analysis Situs, the Foundations of Mathematics and a Geometry of Space
}

\author{
Vincenzo De Risi
}

\section{To cite this version:}

Vincenzo De Risi. Analysis Situs, the Foundations of Mathematics and a Geometry of Space. The Oxford Handbook of Leibniz, ed. M.R. Antognazza, Oxford, Oxford University Press 2019, pp. 247-58., Oxford University Press, pp.247-258, 2018, 10.1093/oxfordhb/9780199744725.013.22 . hal-03059623

\section{HAL Id: hal-03059623 \\ https://hal.science/hal-03059623}

Submitted on 12 Dec 2020

HAL is a multi-disciplinary open access archive for the deposit and dissemination of scientific research documents, whether they are published or not. The documents may come from teaching and research institutions in France or abroad, or from public or private research centers.
L'archive ouverte pluridisciplinaire HAL, est destinée au dépôt et à la diffusion de documents scientifiques de niveau recherche, publiés ou non, émanant des établissements d'enseignement et de recherche français ou étrangers, des laboratoires publics ou privés. 


\section{Analysis Situs, the Foundations of Mathematics and a Geometry of Space}

Vincenzo De Risi

Analysis situs is the name given by Leibniz to a cluster of mathematical and philosophical investigations into the foundations, development, and formalization of geometry. Leibniz devoted himself to this multifaceted project throughout his life: his earliest studies date back to the Parisian period (1672-1676), and his last drafts were composed at the end of his life (17141716). These forty years' worth of efforts yielded some hundreds of essays that range from short collections of notes to complex, long and highly developed manuscripts. None of these works, however, was published during Leibniz's lifetime. His contemporaries' dismissive attitudes towards the project, as well as Leibniz's own conviction that his new discipline had yielded nothing of great consequence for the field of geometry, ${ }^{1}$ prevented Leibniz from seeking publication. ${ }^{2}$ Some of his writings on analysis situs were printed in $19^{\text {th }}$-century Leibniz editions, while others have only been published in recent years. ${ }^{3}$ The great bulk of Leibniz's studies on the topic, however, remains unpublished in the Hannover library. Nevertheless, we have enough material to attempt to reconstruct-albeit partially and tentatively-the main aims, developments and outcomes of Leibniz's endeavor in a new geometry.

\footnotetext{
${ }^{1}$ Here some complaints from the well-known letter to L'Hospital from 27 December 1694 (in GM 2, 255-62): “My metaphysics is all mathematics, so to speak, or it can become so. At the present, I dare not publish my projects on the characteristica situs because, unless made believable through examples of some importance, it would be regarded as just a vision. Nonetheless I see in advance that it will not fail."

${ }^{2}$ Leibniz was particularly influenced by Huygens's poor reception of the nascent characteristica geometrica in his letter of 22 November 1679 (A III, 2, 888-89).

${ }^{3}$ Leibniz's papers on analysis situs are mostly to be found in volumes 5 (from 1858) and 7 (from 1863) of Gerhardt's edition of the Mathematische Schriften, but some of them are also printed in Couturat's Opuscules et fragments inédits. Further publications include an important text in the appendix of M. Mugnai, "Leibniz's Theory of Relations," Studia Leibnitiana Supplementa 28 (1992); the essays published in G.W. Leibniz, La caractéristique géométrique, eds. J. Echeverría and M. Parmentier (Paris: Vrin, 1995); and the appendix to V. De Risi, Geometry and Monadology. Leibniz's Analysis Situs and Philosophy of Space (Basel: Birkhäuser, 2007).
} 


\section{A New Formalism}

The concept of situation (situs) is, roughly speaking, the notion of the position of an object (or a figure) in space relative to other objects. Thus, from the very beginning of Leibniz's investigations, it is considered a relational predicate: and it also is, as it were, the first source of Leibniz's later and celebrated theory of a relational space. In Leibniz's times, the notion of situation was widely employed in metaphysics, where the concept evolved from the Aristotelian category of $x \varepsilon i \sigma \theta \alpha$, i.e. situm esse. ${ }^{4}$ Its mathematical genealogy is long and complex, and indeed it can be traced back (again) to Aristotle's definition of a point as a "monad with position" ( $\theta \dot{\varepsilon} \sigma \iota \varsigma$, that is positio or situs ${ }^{5}$. In this connection, it was found in a number of geometrical books of the Early Modern Age, remaining, however, a philosophical definition and a concept without consequences on the mathematical practice. ${ }^{6}$ The only geometrical studies that made some use of situation were treatises on the theory of perspective, and it is not unlikely that Leibniz was inspired by Pascal's studies on perspective geometry, which he could have read in manuscript form in the 1670 s, but which are now almost entirely lost. ${ }^{7}$ The idea of a geometria situs, however, belongs fully to Leibniz.

The primary motivation for Leibniz's research seems to stem from the common $17^{\text {th }}$-century epistemological concern regarding the use-and abuse - of new algebraic methods in geometry. Most mathematicians had to admit that Viète's, Fermat's and Descartes's new algebraic methods were incredibly fruitful for the development of geometry, and no one could deny that they were an extraordinary tool in the mathematical art of discovery. ${ }^{8}$ Moreover, the new algebra needed not to rely on diagrammatic reasoning, successfully escaping the many traps of imagination in synthetic geometry. Widespread and often well-founded concerns, however, were raised about the foundations of the algebraic methods, their appropriateness to the domain of geometry, their extent and soundness in demonstration, their simplicity in definitions and proofs. Leibniz probably praised the advantages of a cogitatio caeca in mathematics (and metaphysics) more than

\footnotetext{
${ }^{4}$ Aristotle's classical loci are Cat. 4, $1^{\mathrm{b}} 27$ and Top. A 9, 103 23 . A modern and relational interpretation of the category of situation can be found, for instance, in Descartes's Principia, II, 15 (AT VIII, 48-49).

${ }^{5}$ See Metaph. $\Delta$ 6, 1016 $24-26$. The definition is in fact Pythagorean and probably predates Aristotle: see Proclus Diadochus, In Primum Euclidis, ed. G. Friedlein (Leipzig: Teubner, 1873), 95. Leibniz's correction of Euclid's definition of a point in this direction is to be found in his In Euclidis $\pi \rho \tilde{\omega} \tau \alpha$, in GM 5, 183: "I. 'A point is what has no parts'. One must add that it has situation. Otherwise also the temporal instant and the soul were points." An instant, for Leibniz, is endowed with positio, which is the basic order-relation, but not with situs, which is a position in a co-existent order. According to Leibniz, souls (i.e. monads) have neither situation nor position.

${ }^{6}$ Proclus had already reproached Aristotle for his philosophically motivated revision of the definition of a point, to which he had added the notion of situation. Proclus regards this move as useless from the mathematical standpoint: see Proclus, In Primum Euclidis, 93. Such criticisms of Aristotle were not uncommon in the Modern Age, when mathematicians could not yet envision a geometrical use for the notion of situation. See, for instance, Barrow's third lecture on mathematics, in I. Barrow, The Mathematical Works, ed. W. Whewell (Cambridge: CUP, 1860), 62. A clumsy (but mathematical) reference to the notion of situation is also to be found in Francesco Patrizi's Della nuova geometria (Ferrara: Baldini 1587) and in Campanella's unpublished writings. It is very unlikely that Leibniz might have been influenced by Patrizi's (or Campanella's) work, that he probably only read during his Italian trip (in 1690; see A VI, 4, p. 966) but, in any case, these works show that the notion of situation had penetrated to the foundational studies on geometry in the $17^{\text {th }}$ century.

${ }^{7}$ Leibniz's reading of Pascal's writings on geometry dates to the end of the Parisian Period, 1675-1676, when Leibniz also recommended that Pascal's manuscripts be published: but the edition was never done, and the papers went lost. Today, we only have Leibniz's own transcriptions of a few pages of them. On the history of Pascal's papers, see J. Mesnard, “Leibniz et les papiers de Pascal," Studia Leibnitiana Supplementa 17 (1978): 45-58. Cf. also R. Taton, ed., L'oeuvre scientifique de Pascal (Paris: PUF, 1964).

${ }^{8} \mathrm{On}$ symbolic reasoning as an ars inveniendi in geometry, see for instance Leibniz's De constructione, in GM 7, 24960 .
} 
anyone else. He too, however, worried (somewhat more than others) about the foundations of such symbolic methods. Algebra is a useful tool for the geometer, but the formalism has the potential to yield unsound conclusions, i.e., it proves too much, as symbols in ordinary algebra have no straightforward geometrical interpretation and may denote magnitudes that have no meaning in (classical, Euclidean) geometrical terms (e.g. imaginary numbers, or highdimensional products $\left.{ }^{9}\right)$. It is not even clear that algebra can demonstrate all the relevant geometrical results (it might prove too little), for its completeness could be hindered by the purely numerical origins of the formalism, which was not originally devised to solve geometrical problems. The foundations of ordinary algebra, moreover, are mostly obscure, and its rules seem to lie (also) in some geometrical results (such as Pythagoras's theorem), which makes it impossible to rely on algebra in the context of geometrical justification.

Leibniz's proposes to assuage these concerns by eliminating algebra from geometry without eliminating symbolic reasoning. His aim is thus to construct a characteristica geometrica propria, a new formalism for geometry, whose constants and variables range directly over points and figures in space (instead of magnitudes and numbers), whose primary relations consist in congruence and similarity (instead of equality), and whose most important and in fact unique function (instead of addition or multiplication) is situs, i.e. a function concerning reciprocal spatial position between geometrical figures. This new formalism is therefore capable of solving all the aforementioned problems (and a few more), all of which were caused by the unnatural use of an algebra of magnitudes (the ordinary Cartesian algebra) in place of an algebra of situations. ${ }^{10}$

Leibniz developed this new characteristica up to a fairly good level of sophistication, providing new symbols for functions and undefined relations, formal definitions of elementary geometrical figures (such as a straight line, a circle, a plane, etc.), and a few basic spatial configurations (angles, parallelism), as well as a number of formal axioms concerning the situational relations themselves (e.g. reflexivity, symmetry and transitivity of congruence, and similarity). He also managed to demonstrate a small number of very elementary theorems, that are often remarkable for their abstract form and foundational relevance, and would not unworthily feature in much more mature treatises on the foundations of geometry. ${ }^{11}$

Ultimately, these formal axioms also provide a characterization (indeed, an implicit definition) of the notion of situs, the fundamental function of the system. This turns out to be nothing more than the notion of distance, and is mainly defined with reference to the concept of congruence: two collections of objects have the same reciprocal situations if and only if one collection is congruent with the other. For instance, the extremities of two segments of equal length, or the vertices of two triangles with equal sides, or the set of points of a circumference with respect to those of another circumference with equal radius all have the same reciprocal

\footnotetext{
${ }^{9}$ For a survey on imaginary numbers, see for instance R.B. McClenon, "A Contribution of Leibniz to the History of Complex Numbers,” The American Mathematical Monthly 30 (1923): 369-74.

${ }^{10}$ A very good formulation of this program can be found in Leibniz's essay on Ars Representatoria, in V. De Risi, "Leibniz on Geometry. Two unpublished manuscripts with translation and commentary," The Leibniz Review 15 (2005): 127-51. Cf. also $\$ \$ 2-7$ of the Characteristica geometrica, GM 5, 141-44; and De analysi situs, in GM V, 182-83.

${ }^{11}$ Many mathematicians working on the foundations of geometry in the late $19^{\text {th }}$ century knew something about Leibniz's work on analysis situs (through Gerhardt's edition). Peano sent a collaborator of his to Hannover to look at the Leibnizian manuscripts, and Couturat himself became involved in the Leibniz studies in this way. Pasch's work is probably the most similar to Leibniz's. Peano, Pieri and Veronese mention him explicitly. Hilbert's work, on the contrary, departs drastically from Leibnizian geometrical practice.
} 
situation. The system of situations is thus the structure of reciprocal distances between the points of a figure. ${ }^{12}$

This shows that the (Euclidean) metric relations between figures or points are in fact the main subject of Leibniz's analysis situs. Thus, his new geometry presents no more generality (in this respect) than classical Euclidean geometry does. It is remarkable, however, that Leibniz also seems to explore some more general mathematical structures in his first studies on a geometrical formalism. On the one hand, his formal axioms and purely combinatorial techniques of proof allow him to demonstrate a number of results that allow for different geometrical systems. Leibniz is aware, for instance, that a number of the properties of a straight line that he can deduce from his axioms and definitions apply with equal force to the great circles on a sphereand he points out the structural resemblances between them with respect to axioms of congruence. ${ }^{13}$ On the other hand, Leibniz's emphasis on the importance of a number of geometrical relations besides congruence, especially the relevance of the notion of similarity, seems to point in a non-metrical direction-towards something which falls just short of a true geometry of projections. ${ }^{14}$ One should not, however, overemphasize these kinds of developments: Leibniz will abandon them soon, and they seem to be more a by-product of his combinatorial approach to geometry than a real aim to the edification of a geometria situs. ${ }^{15}$

\section{The Foundations of Geometry}

In fact, the development of a characteristica geometrica occurred mostly in the early stages of Leibniz's reflections on geometry, and parallels and complements his earlier research of the late 1670 s and the early 1680 s on a characteristica universalis-although they keep surfacing again from time to time in the mature years. Be it as it may, the subsequent elaboration of Leibniz's thoughts in geometry proceeds through a thorough study of classical elementary geometry (mainly read on Clavius's edition of the Elements), which dispels any leaning toward new geometries but enormously enriches Leibniz's skills in foundational analysis as well as the concreteness of his approach to the most debated problems of synthetic geometry. The analysis situs acquires new aims and perspectives: it becomes a tool designed to rigorize and ground the

\footnotetext{
${ }^{12}$ Some of the most important examples thereof come from the ample Characteristica geometrica from 1679, in GM 5, 141-68; much more material can be found in the preparatory drafts of this essay, in Leibniz, La caractéristique géométrique.

${ }^{13}$ See GM 5, 146-47.

${ }^{14}$ Since Leibniz's geometrical writings were first published at the heyday of projective geometry, a number of mathematicians assumed that any foundational study that employed the notion of similarity had to be "projective" in some sense. There are no traces, however, of a theory of projections in Leibniz's papers on analysis situs, and there is also no evidence of a non-metric geometry in the proper sense. Like Desargues and other $18^{\text {th }}$-century perspective geometers, Leibniz uses non-metric-preserving transformations (like similarity) only to demonstrate metric resultsfor instance, Elements XII, 2 (see for the relevant texts: A VI, 4, 378-82; GM 5, 182; GM 7, 24 and 276-77; Mugnai, Leibniz's Theory of Relations, 145-56; De Risi, Geometry and Monadology, 625-26). This is not to say that Leibniz did not also work on perspective geometry; see J. Echeverría, "Recherches inconnues de Leibniz sur la géométrie perspective," Studia Leibnitiana Supplementa 23 (1983): 191-202; and V. Debuiche, "Perspective in Leibniz's Invention of Characteristica Geometrica : The Problem of Desargues's Influence," Historia Mathematica, forthcoming.

${ }^{15}$ In this respect, the widespread idea that Leibniz's analysis situs was an anticipation of Graßmann's work on vector calculus, although deeply flawed, had the advantage of pointing towards some important metric results that Leibniz could have obtained through his combinatorics; cf. H. Grassmann, Geometrische Analyse geknüpft an die von Leibniz erfundene geometrische Charakteristik (Leipzig: Weidmann, 1847). The alleged connection between Leibniz's geometrical researches and topology, however, seems to derive only from the fact that this latter discipline was usually called "analysis situs" in the $19^{\text {th }}$ century.
} 
geometrical sciences. Leibniz produces a number of remarkable essays filling the gaps of the Euclidean (or Early Modern) demonstrations of some classical results, and his insistence on the need of continuity assumptions in elementary proofs, for instance, or a better foundation for the use of rigid motions and superposition marks a clear advancement in the understanding of the proof-theoretic structure of geometry. ${ }^{16}$

Leibniz's aims, however, are not limited to an enhancement of rigor in demonstration. He would like to be able to prove all the geometrical axioms. This desire, which may appear strange today, was in fact commonplace at the time, and Clavius himself (perhaps the most influential geometer of the Modern Age) included after the Euclidean postulates and common notions their "demonstrations." Leibniz's general idea is that the need for an axiom betrays a need for a better definition. ${ }^{17}$ It is Euclid's infamous and obscure definition of a straight line, for example, that obliged him (or modern geometers) to provide axioms that implicitly characterize it (there is only one line between any two points) and postulates that assume its possibility (there is at least a line between any two points). But with better definitions, like the ones that Leibniz himself tried to mould, axioms and postulates are proven via an analysis of definitions. For instance, given the definition of a straight line as a self-congruent line (roughly, as an axis of rotation), it follows straightforwardly, Leibniz claims, that only one such line can be traced between two points. The result should be the foundation of geometry as a perfectly unhypothetical and analytical science—which has been regarded as Leibniz's peculiar "logicist" approach to mathematics. ${ }^{18}$

Of course, Leibniz was well aware that the definitions themselves call for some proof-for they have become principles of demonstration, not just stipulations upon words. Indeed, he argues that all definitions should be real, which means that they must show the possibility of their objects. If one asks, now, on which grounds Leibniz could hope to demonstrate the real possibility of the objects of geometrical definitions, the answer points at the very concept of a geometrical space. This concept is, in fact, the most relevant advancement that Leibniz made in the field of geometry throughout his whole attempt to construct an analysis situs.

\section{The Geometry of Space}

In Antiquity, the subject matter of geometry was thought to be (continuous) quantities, or magnitudes, like circles, straight lines, triangles or conic sections-not space. Anyone who went through the thirteen books of Euclid's Elements looking for a single reference to "space" or "place" would be sorely disappointed. The Late Antiquity did have some notions of a spatial extension endowed with quantitative properties, but these notions remained largely disconnected from mathematics. Much later, some geometers and philosophers of the late Renaissance built on these Neoplatonic conceptions and developed notions of space that could have mathematical import, but the main aims of these speculations remained purely metaphysical, and the seminal concept of a geometrical space was entirely disconnected from actual mathematical practice. Even well known understandings of space from the Early Modern Age, from Descartes's res extensa to

\footnotetext{
${ }^{16}$ See for example: A VI, 4, 165 and 970, and the text Demonstratio omnimoda, in De Risi, Geometry and Monadology, pp. 601-3.

${ }^{17}$ See Nouveaux Essais, IV, 12, \$ 4; A VI, 6, 451. But also: A II, 2, 103; A VI, 4, 197.

${ }^{18}$ See at least: A II, 1, 351 (=A III, 1, 14); A II, 1, 769-71; A II, 2, 490-91; A III, 7, 113; A VI, 4, 165; A VI, 4, 703705; A VI, 4, 969-70. This project was widely discussed in L. Couturat, La logique de Leibniz (Paris: Alcan, 1901), which contains the first extended treatment of Leibniz's analysis situs. Although Leibniz's injection of logic into geometry was remarkable, one has to consider that the foundations of Leibniz's geometrical system are to be found in the metaphysical definition of space as a total situational order, which cannot be reduced to logic alone. A very good discussion of the relations between logic and mathematics in that era is M. Mugnai, "Logic and Mathematics in the Seventeenth Century," History and Philosophy of Logic 31 (2010): 297-314.
} 
Newton's absolute space, were devoid of proper mathematical attributes and remained a sort of amorphous background that only played the role of a screen in which the geometer traces those figures and magnitudes that still are the true objects of his science.

It is very difficult to fully reconstruct the complex $17^{\text {th }}$ - and $18^{\text {th }}$-century developments that gave birth to modern geometry as the science of space. This transformation required that one understand space as a structure that can be endowed with intrinsic geometrical properties and investigated with mathematical methods. This same train of thought would eventually contribute to the development of the concept of a plurality of possible spaces, which in fact make their first appearance in the late $18^{\text {th }}$-century studies on projective and non-Euclidean geometries.

In some sense, however, this whole evolution of geometry began with Leibniz's writings on analysis situs. Here, for the very first time in the history of mathematics, we find geometrical definitions of space, followed by axioms and theorems about it, and the first ever demonstrations having as their object the properties of space itself.

The point of departure is Leibniz's celebrated definition of space as an order of situations. ${ }^{19}$ Given the notion of situs as distance, the definition means that space is the system of all (possible) distances between objects. In modern terms, we would say that Leibniz's notion of space is that of an abstract metric space. The terms of the situational relations (the related objects) remain abstract elements: they are bodies in physical space, but figures and points in geometrical space. ${ }^{20}$

Space is thus a structure, and extension is produced by a certain order of distances between points. Leibniz can thus say that space itself is constituted by points ("constitui, dico, non componi" ${ }^{21}$ ). It is not composed of points, for obviously a number of unextended points, and even an infinite number of them, could not (considered as an aggregate or a merely quantitative whole) build up anything extended. But a set of points as situational elements, that is, a set of points with a structure, with a system of reciprocal distances - this may indeed yield extension out of situation. As we can see, this is a very modern, "structuralist" way out of the labyrinthus continui. $^{22}$

Starting with this definition of space, Leibniz singles out a number of properties that an abstract order of situations may or may not possess. Leibniz's definitions of these properties represent a remarkable feat in geometry, since most of them were constructed for the first time by Leibniz himself, and almost all of them require a high degree of conceptual sophistication. To give the most important examples, in the writings on analysis situs we find: a good definition of isotropy (in general, and not restricted to the Euclidean metric), which Leibniz calls uniformity; a

\footnotetext{
${ }^{19}$ See for instance the Fifth Paper to Clarke, $\$ 104$, in GP 7, 415. The definition is however very common in Leibniz's late years.

${ }^{20}$ In this structural definition, a point may be any object considered simply as a situational term. Cf. a text in De Risi, Geometry and Monadology, 624. The definition is already in Pascal, Introduction à la géométrie, now in D. Descotes, ed., Géométries de Port-Royal, (Paris: Champion, 2009).

${ }^{21}$ GM 6, 370.

${ }^{22}$ This appears to be a late discovery, and many writings on situational analysis dating to the 1670 s and 1680 s are still uncertain on the possibility of grounding extensio on situs (see, for instance, the texts published in Leibniz, $\mathrm{La}$ caractéristique géométrique, 138; and in De Risi, Geometry and Monadology, 588 and 624). A clear presentation of Leibniz's views on the topic in his young and early mature years is offered in G.W. Leibniz, The Labyrinth of the Continuum. Writings on the Continuum Problem, 1672-1686, ed. R.T.W. Arthur (New Haven: Yale, 2001). The editor thereof made a great deal of important contributions with respect to clarifying Leibniz's conceptions of continuity and extension; concerning the views presented here, cf. his seminal paper: R.T.W. Arthur, "On the Unappreciated Novelty of Leibniz's Spatial Relationism," in Leibniz. Tradition und Aktualität. V Internationaler Leibniz-Kongreß, Hannover 1988; as well as his recent R.T.W. Arthur, "Leibniz's Theory of Space," Foundations of Science 18 (2013): 499-528. On analysis situs and continuity, cf. also J.-P. Alcantara, Sur le second labyrinthe de Leibniz (Paris: L'Harmattan, 2003).
} 
definition of homogeneity that contains as a germ of the modern concept of a manifold; some studies on the notion of dimensionality; a large number of very good definitions of continuity taken either as the modern notion of connection, or as linear completeness (with a few outcomes that are not too far from Dedekind's theory of cuts); and reflections on the properties of Euclidean metric. $^{23}$

From this point of view, we can reformulate Leibniz's foundational program in geometry as follows. He defines absolute space as the total and all-encompassing order of all possible situations. This is just our notion of a metric space (and it is unrelated to inertial properties). From this basic concept, Leibniz would like to deduce an incredible number of highly characterizing space-properties. He would like to prove, in fact, that the very notion of a total situational order entails that this order generates an extension, that it is "uniform" and "homogeneous", necessarily "continuous", necessarily tri-dimensional, necessarily Euclidean, and so on. To give these proofs, he embarks on the utopian project, half philosophical and half mathematical, of demonstrating many important Euclidean theorems and axioms, taking his new geometry of space as its starting point. Especially remarkable are Leibniz's many and varied attempts to prove the Parallel Postulate, which predate the more famous (and more developed) attempts made by Saccheri, Lambert and Legendre and are made in the context of a general theory of space that not many of those later geometers were able to envision. ${ }^{24}$ His progress in the field is, obviously, very limited (not only regarding the Euclidean Axiom), and he was aware of the many shortcomings of his demonstrations. Thanks to these (alleged) results and these very rich geometrical properties of space itself, Leibniz could be able to prove the real possibility of all the elementary definitions of geometry. From these definitions, as we have seen, the whole classical geometry would follow. It seems that his foundational project in geometry was indeed closely linked with his new conception of space as a situational order.

The actual products of the analysis situs as an analysis of the concept of space are thus very poor, both because Leibniz's grand project of founding all of the principles of Euclidean geometry on the abstract concept of a metric space was clearly doomed to failure and because the actual geometrical arguments he offers are seldom worth the effort of any serious mathematician. It would be hard, however, to overestimate the significance of this project to the development of mathematics: space has indeed become a geometrical structure instead of a metaphysical amorphous extension external to geometry, and geometry itself is no longer concerned with triangles and circles, but has rather attained its modern status as a science of space.

\section{Geometry and Metaphysics}

The remarkable, although very imperfect, fruits of Leibniz's investigations into a new geometry were reaped in later years so as to yield even more remarkable advancements in philosophy. In fact, from at least the 1690s, though chiefly after the turn of the century, Leibniz's writings on analysis situs were often integrated into more general considerations of metaphysics and the theory of knowledge, and his openly philosophical essays, in turn, bear traces of the many private experiments that Leibniz attempted in his mathematical studies.

This attitude is especially significant for the development of a theory of sensible knowledge, which Leibniz seems to have first developed around the time that he was composing Nouveaux

\footnotetext{
${ }^{23}$ The relevant texts are mostly to be found, and discussed, in De Risi, Geometry and Monadology, 178-264. On the connection between analysis situs and the theory of space, see also the contribution of David Rabouin in T. Paquot, C. Younès (eds.), Espace et lieu dans la pensée occidentale (Paris: Editions La Découverte 2012).

${ }^{24}$ Most of Leibniz's essays on parallel theory remain unpublished. The In Euclidis $\pi \rho \tilde{\omega} \tau \alpha$, in GM 5, 200-4, offers however as much as sixteen different attempts to prove the Postulate.
} 
Essais. The theory ultimately tends towards an epistemology of spatial perception. The main tool employed by Leibniz seems to be his earlier definition of geometrical similarity through coperception (two objects are similar if they can only be distinguished through co-perception, but not if considered one by one), ${ }^{25}$ which not only injects phenomenological elements into the foundational attempts in mathematics but also adds a geometrical twist to the theory of perception itself. The relations of co-existence and co-perceptibility that obtain between objects are clearly identified with situational relations, a notion that allows for a characterization of space as the order of co-existence, or simultaneous perception (or perceptibility), a concept connected in turn to Leibniz's theory of clear and confused ideas and many other phenomenological issues. Some characterizations of the principle of the identity of indiscernibles in its perceptual form are clearly linked to the geometrical notions of congruence and similarity, and even modal concepts that touch on the theory of possible worlds find their perceptual and geometrical correlate here. In some of his latest essays, ${ }^{26}$ where the connection between situational analysis and sensible perception is carried to its furthest extreme, Leibniz seems inclined to define of space as a form of sensible perception (almost in Kantian terms) and even, to some extent, to posit a "transcendental" determination of space itself. ${ }^{27}$

The importance of Leibniz's studies on analysis situs is also apparent in his celebrated exchange with Clarke. In fact, we know that a number of drafts on the geometria situs were written in the very same months of that famous correspondence, and Leibniz seemed to intend to publish at least some of them in those late years. Indeed, he clearly imagined that the a developed analysis situs might serve as mathematical support for his metaphysical position. In any case, it is certain that Leibniz's geometrical studies shed a great deal of light on his late conception of space as it is defended against Newton and Clarke. Many of the issues debated there about Leibniz's relational notion of space and motion are better understood as declinations of his new, structural approach to a geometry of space. In this connection, even the issues about the theory of inertia and absolute space seem to be just corollaries and scholia to a bigger mathematical and epistemological quarrel about the very object of geometry and its definition.

Lastly, I will mention the fact that Leibniz's definition of space as a structure and a system of relations paves the way for a better understanding of the much vexed question of the relationship between monads and bodies. As we have seen, one of the most notable results of Leibniz's analysis situs is that space can be considered as constituted by points, and extension can be produced by a set of unextended elements endowed with a situational structure. A cosmological picture that presented Leibnizian physical bodies as constituted by monads (thought as point-like substances) in a system of situational relations would be too simplistic to function as a successful reading of the late monadology_but could nevertheless serve to both shed light on some of Leibniz's later declarations about monads and corporeal substances ${ }^{28}$ and to help us construct a reasonable chart of some of the possible outcomes of the later Wolffian and post-Wolffian physical monadologies (taken in a broad sense). Leibniz's own point of view (as I think) is that

\footnotetext{
${ }^{25}$ This definition is found for the first time in Leibniz's letter to Gallois from September 1677, in A II, 1, 380; A III, 2, 227-28.

${ }^{26}$ For example the Initia rerum mathematicarum metaphysica from 1715 , whose original title was De calculo situs (GM 7, 17-29). But see also the (early) $\$ \$ 105-8$ of the Characteristica geometrica, which were not published by Gerhardt and can be read in Leibniz, La caractéristique géométrique, 228-32.

${ }^{27}$ For a discussion of the very complex phenomenological and transcendental elements of Leibniz's project of an analysis situs, I cannot but refer to my Geometry and Monadology, 297-428. The first discussion of Leibniz's geometrical ideas in relation to his theory of knowledge and metaphysics is to be found in E. Cassirer, Leibniz' System in seinen wissenschaftlichen Grundlagen (Marburg: Elwert, 1902), which unfortunately enjoyed no great favor in subsequent scholarship on the topic.

${ }^{28}$ On the issue, see D. Garber, Leibniz: Body, Substance, Monad (Oxford: OUP, 2009).
} 
monads (as soul-like substances) are not situated at all-they are not in space. But we perceive them by expressing their intermonadic (non-spatial) relations as situational relations, i.e. as a spatial extension. Here exprimere means something like an isomorphic image, a representation that does not preserve the inner nature, but the order and structure of the relations involved..$^{29}$ So that, in the end, we can (more or less) faithfully represent through situational relations what happens in the supersensible realm, and perceive monads as phenomena (bodies) in space. In this theory, we finally integrate all aspects of Leibniz's late epistemology of sensible perception, his metaphysical thoughts on monads and space, and his most daring mathematical results. I will not belabor the interpretation of the connection between monads and phenomena through situation, as it is very complicated. ${ }^{30}$ However, I wish to point to the fact that such a conception is entirely reliant on the mathematical notion of expression as an isomorphism, and the geometrical discoveries about the structural nature of space associated with the analysis situs.

\section{Conclusions}

Leibniz's writings on analysis situs were lost to the mathematical and philosophical tradition of the Modern Age. His metaphysical conception of space, which played such an important role in the development of $18^{\text {th }}$-century philosophy, remained partial and undefended without its natural complement of geometrical investigation, and the problem of the composition of the continuum, or the relation between monads and space, was left unsolved by the Wolffian tradition.

The very idea of an analysis situs, however, surfaced already in the few Leibnizian works published in the Eighteenth Century, and engendered a large debate on these topics and a quarrel between Euclidean defenders of a geometry of figures against the new geometry of space. The dream of a new geometry was pursued in Leibniz's name, and new and un-Leibnizian methods were devised in order to answer geometrical and philosophical questions that Leibniz had already addressed in his unpublished writings. Many scientists and philosophers claimed that they understood what Leibniz had envisaged with his studies; Wolff, Euler, Buffon, Lambert, Kant, Carnot, Graßmann, Klein, Riemann, Poincaré: all of them relied on Leibniz to illustrate their own attempts to construct a new geometry-and sometimes a new metaphysics that hinged on mathematical results. Vector calculus, projective geometry, topology were in turn recognized as the proper analysis situs and ascribed to Leibniz, even though they departed greatly from Leibniz original ideas. The failed publication of Leibniz's writings, in this sense, proved to be even more effective towards the development of modern geometry, and his fragmentary suggestions and the spell of a name-analysis situs_-produced in the end greater revolutions than he had expected.

\footnotetext{
${ }^{29}$ On the concept of expression as an isomorphism, see at least: M.A. Kulstad, "Leibniz Conception of Expression," Studia Leibnitiana 9 (1977): 55-76; C. Swoyer, "Leibnizian Expression," Journal of the History of Philosophy 33 (1995): 65-99; V. Debuiche, "La notion d'expression et ses origines mathématiques," Studia Leibnitiana 41 (2009): 88-117.

${ }^{30}$ See again De Risi, Geometry and Monadology, 486-550.
} 